\title{
Autonomic Blockade by Propranolol and Atropine to Study Intrinsic Myocardial Function in Man
}

\author{
ANTHONY D. Jose and Roger R. TAYLOR \\ From the Hallstrom Institute of Cardiology, Sydney, Australia
}

\begin{abstract}
A B S T RACT Blockade of cardiac autonomic nervous activity by an intravenous injection of $0.2 \mathrm{mg} / \mathrm{kg}$ propranolol and $0.04 \mathrm{mg} / \mathrm{kg}$ atropine was used with cardiac catheterization to study intrinsic cardiac function in 47 patients with normal hearts and known graded myocardial disease. After blockade, significant hemodynamic abnormalities became apparent at rest in the majority of patients with known disease, many of whom had normal control findings. This occurred partly through a reduction in the normal range of cardiac function at rest, and partly through changes in the abnormalities associated with disease: after blockade, diseased hearts had normal stroke volumes, but beat more slowly, and had higher left ventricular filling pressures. The heart rate after blockade was fixed; this was defined as the intrinsic heart rate (IHR) ; it ranged from 57 to 126 beats/ min in different patients. Both the IHR and left ventricular end-diastolic pressure after blockade were sensitively and quantitatively related to the severity of myocardial disease. When, after blockade, arterial pressure was raised by angiotensin, the IHR was unchanged; normal hearts maintained their stroke volume and increased stroke work; diseased hearts maintained stroke volume less well and stroke work was unchanged or fell. Abnormal ventricular responses corresponded well with abnormal ventricular function at rest.
\end{abstract}

In different patients the IHR was significantly related to each available index of left ventricular function. Other studies in animals have shown that the IHR is closely related to intrinsic myocardial contractility in certain forms of experimental heart failure. An analogous relationship existing between the IHR and myocardial function in patients with heart disease is suggested as the explanation for the IHR/ventricular func-

This work was presented in part to Annual Meetings of the Cardiac Society of Australia in Sydney, May 1963 (1), and in Melbourne, May 1965 (2), and to the Symposium on Beta-Adrenergic Blockade, Buxton, England, November 1965 (3).

Received for publication 14 February 1969 and in revised form 26 June 1969. tion relationship in this study. If so, the IHR may prove valuable as an index of myocardial function in man, since it can be measured simply and safely in clinical practice.

\section{INTRODUCTION}

Methods for the assessment of abnormal myocardial function in man must for practical reasons depend on comparisons of cardiac performance with normal hearts studied under similar conditions. None has so far proved entirely satisfactory, either in theory or in practice. Several major difficulties have yet to be overcome: inability to equate the effects of extracardiac stimuli on cardiac performance in different individuals; inability to make accurate allowance for the effects on cardiac performance of altered work loads, muscle hypertrophy and fibrosis, and chamber dilatation; and inability to describe muscle contractility in absolute units suitable for comparison in different individuals. We have attempted in this study to overcome the first of these three difficulties.

It is known that in animals, cardiac performance is regulated by separate intrinsic (or myogenic) and extrinsic (or neurohumoral) mechanisms (4), and that normally these two superimpose, each tending to obscure the other (5). In man, therefore, although myocardial disease must affect primarily the intrinsic properties of cardiac muscle, it has not been possible to study these without interference from extrinsic stimuli. The assumption that extrinsic stimuli have equal effects on cardiac performance in different patients must frequently be in error. The pattern of these stimuli not only varies with personality and with environmental factors in each subject, but also differs systematically between normal subjects and those with heart disease. Reduction of the normal vagal inhibitory influence on the heart at rest was shown many years ago (6) and there is convincing evidence of abnormally increased adrenergic activity in patients with heart failure (7). Measurements of cardiac performance made in the ab- 
sence of such extrinsic stimuli should therefore provide more comparable data in different individuals from which to assess ventricular function.

This approach was made practicable in man by the development of the beta-adrenergic blocking agent propranolol (8), with which it was possible to inhibit adrenergic activity in the heart without at the same time preventing the regulation of peripheral vascular resistance by alpha-adrenergic stimuli. By giving a single intravenous injection of propranolol and atropine together in sufficient doses, a period of autonomic blockade of the heart was produced, during which its performance could be assessed in relation to its prevailing filling and ejection pressures. Extensive trials were made of the feasibility and safety of this procedure, both in animals and in man; it was then applied during left heart catheterization in selected patients with normal hearts and known myocardial disease. Measurements of left ventricular performance were made at rest before and after autonomic blockade; the left ventricular response to an increase in arterial pressure produced by angiotensin was then measured, after autonomic blockade.

\section{Preliminary studies}

Tolerance to propranolol and atropine. Studies in patients during cardiac catheterization showed that the inclusion of atropine with propranolol prevented episodes of cardiac depression which not uncommonly follow intravenous administration of propranolol alone (9). When injected slowly together, large doses of both drugs were well tolerated by the great majority of patients, even in those with advanced heart disease. The only exceptions were patients with congestive failure of recent onset, with marked venous hypertension, in whom cardiac output and arterial pressure fell abruptly, apparently from systemic venous dilatation.

The noncardiac effects of each drug also appeared less severe when both were given together. Neither urinary retention nor bronchoconstriction occurred, even in patients predisposed to them. Dryness of the mouth and visual blurring were common, but rarely severe.
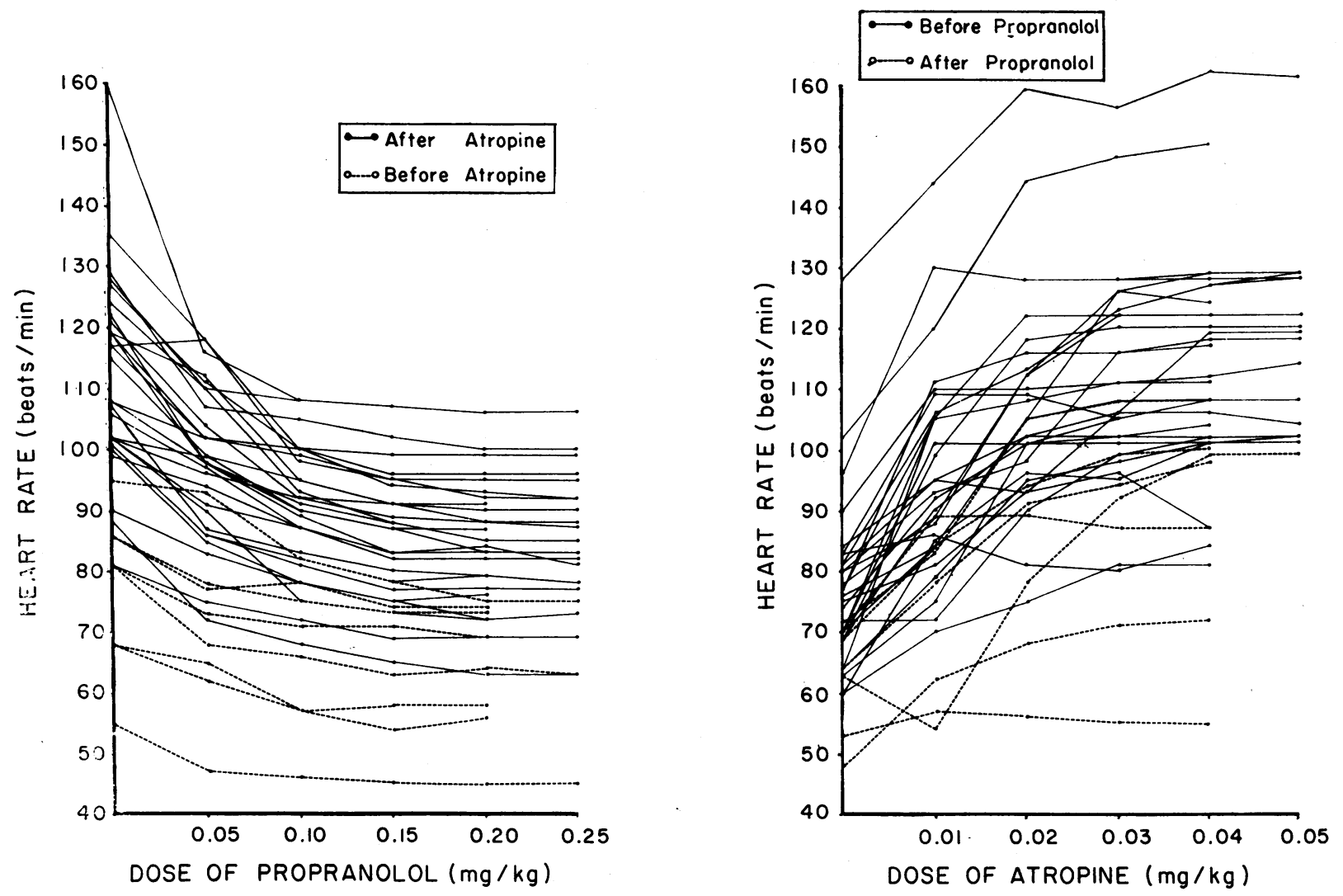

FigURE 1 Serial measurements of heart rate in 36 patients, each 3 min after incremental doses of atropine or propranolol. In 28 cases atropine was given first (solid lines), the control rate rising to a plateau with increasing doses (right); propranolol was then given, the rate falling to its intrinsic level (left). In eight patients this order of administration was reversed (broken lines). 


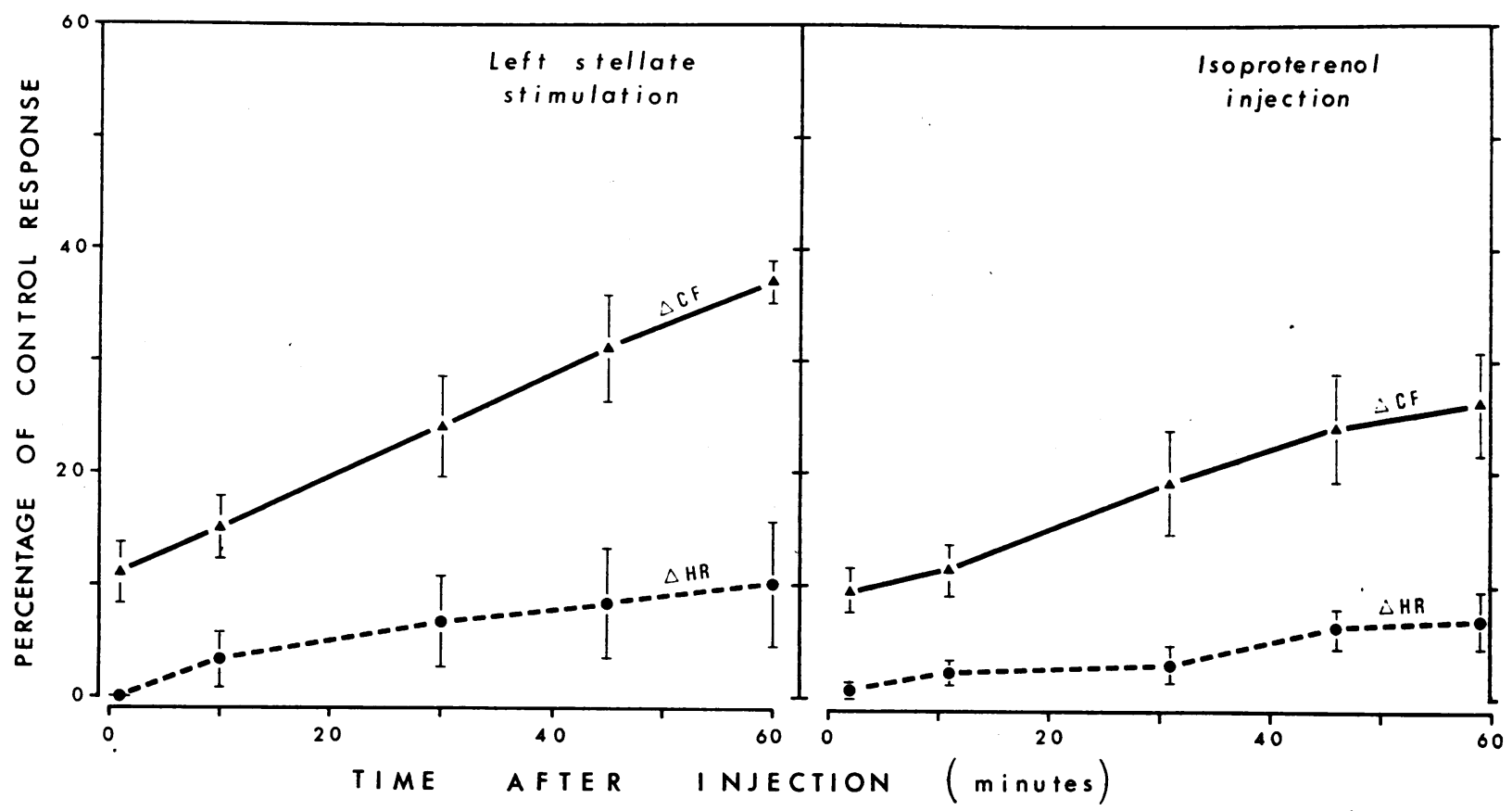

FIGURE 2 Residual peak responses in heart rate and myocardial contractile force to repeated beta-adrenergic stimuli for $1 \mathrm{hr}$ after the intravenous injection of $0.2 \mathrm{mg} / \mathrm{kg}$ propranolol in six anesthetized atropinized dogs. Left: responses to stimulation of the left stellate ganglion; right: responses to single intravenous injections of isoproterenol. Plotted points are mean values of the response in six animals, expressed as percentages of the control response before propranolol, with limits of $1 \mathrm{SE}$.

Doses. 36 patients were studied to assess the doses of each drug required to block autonomic influence on the heart rate (HR) at rest. In each patient, one drug was given first alone, in small intravenous doses repeated at 3-min intervals until there was no further change in $\mathrm{HR}$; then the second drug was given in the same manner until autonomic blockade was complete. HR was recorded over the last $30 \mathrm{sec}$ of each $3 \mathrm{~min}$ interval (Fig. 1). Atropine was given first in 28 patients (solid lines), and propranolol first in 8 (broken lines).

Each of the first four doses of atropine $0.01 \mathrm{mg} / \mathrm{kg}$ caused diminishing but statistically significant rises in HR (Fig. 1, right). The fourth dose caused an average change of $+0.8 / \mathrm{min}(P<0.01)$. A fifth dose given in 15 patients caused no further change $(P>0.5)$.

Each of the first four doses of propranolol $0.05 \mathrm{mg} / \mathrm{kg}$ caused a significant fall in HR (Fig. 1, left). The fourth dose caused an average change of $-0.3 / \mathrm{min}$ $(P<0.01)$. A fifth dose given in 22 patients caused no further change $(P>0.6)$.

Reversal of the order of administration of the drugs did not influence the pattern of HR changes in the study. Nor was this influenced by the presence or absence of heart disease in different patients. It was concluded that a single injection containing $0.04 \mathrm{mg} / \mathrm{kg}$ atropine and $0.2 \mathrm{mg} / \mathrm{kg}$ propranolol would effectively block autonomic influence on the resting HR in man.

"Direct" cardiac effect of propranolol. In 10 patients undergoing cardiac catheterization, $0.04 \mathrm{mg} / \mathrm{kg}$ atropine and $0.2 \mathrm{mg} / \mathrm{kg}$ propranolol were given to inhibit autonomic activity. Then measurements of cardiac performance were made before and after injection of a further $0.2 \mathrm{mg} / \mathrm{kg}$ propranolol. There were no significant changes in HR, intracardiac pressures, or cardiac output, showing that in this dose propranolol had no effect on cardiac function when beta-adrenergic activity was already blocked.

Extent and duration of blockade. The efficiency of 0.2 $\mathrm{mg} / \mathrm{kg}$ propranolol in blocking the cardiac responses to sympathetic stimuli was studied further in six dogs under pentobarbital anesthesia. Myocardial contractile force $(\mathrm{CF})$ was measured from the right ventricle by a Walton-Brodie strain-gauge arch (10), and HR was recorded. Atropine $0.2 \mathrm{mg} / \mathrm{kg}$ was given at $15-\mathrm{min}$ intervals to eliminate vagal responses. Two forms of sympathetic stimuli were used: 10 -sec periods of stimulation of the decentralized left stellate ganglion (by 2-msec pulses of just supramaximal voltage at $20 / \mathrm{sec}$ ), and intravenous injections of $0.4 \mu \mathrm{g} / \mathrm{kg}$ isoproterenol. In the control period before propranolol these stimuli caused 
average increases in $\mathrm{CF}$ of $125 \%$ and $110 \%$ respectively, and in HR of $20 / \mathrm{min}$ and $46 / \mathrm{min}$. The same stimuli were applied at intervals for an hour after the intravenous injection of $0.2 \mathrm{mg} / \mathrm{kg}$ propranolol, with the results shown in Fig. 2.

Responses to nervous and to humoral stimuli were almost equally inhibited. Within $2 \mathrm{~min}$ of the injection, $\mathrm{CF}$ responses were reduced to an average of $10 \%$ of their control values (SD 5\%), and HR responses to less than $1 \%$. Some recovery was evident after $10 \mathrm{~min}$, and the later results suggested a functional half-life for propranolol of approximately $100 \mathrm{~min}$.

These results were consistent with previous studies in animals (8), and with similar but less direct observations in man. The sympathetic stimuli used here were intense, and produced near-maximal inotropic responses from the myocardium. Because propranolol is a competitive blocking agent, the results suggest that weaker stimuli occurring under natural conditions would be completely blocked for practical purposes, for at least $10-20 \mathrm{~min}$ after an injection of $0.2 \mathrm{mg} / \mathrm{kg}$ propranolol.

\section{METHODS}

Patients were studied fasting, lightly sedated with oral pentobarbital 50 or $100 \mathrm{mg}$. Under local anaesthesia, a 17-gauge Ross transseptal puncture needle was introduced from the long saphenous vein to the left atrium, and a polythene catheter passed through it for access to the left ventricle. An 18-gauge Cournand needle was placed in the left brachial artery, and a polythene catheter passed percutaneously from an arm vein to the right atrium.

Control measurements were made of the left heart and arterial pressures, heart rate, and cardiac output. A mixture of $0.04 \mathrm{mg} / \mathrm{kg}$ atropine sulfate and $0.2 \mathrm{mg} / \mathrm{kg}$ propranolol hydrochloride in a volume of $20 \mathrm{ml}$ was then injected into the right atrium over 2-3 min. $5 \mathrm{~min}$ after the end of this injection, the hemodynamic measurements were repeated. Angiotensin II (Hypertensin, Ciba) was then infused into the right atrium at a rate cautiously increased to produce

TABLE I

Mean Hemodynamic Measurements ( $\pm \mathrm{SEM}$ ) in Patients Separated According to Functional Class and to Nature of Disease

\begin{tabular}{|c|c|c|c|c|c|c|c|c|c|c|c|c|c|}
\hline \multirow{3}{*}{\multicolumn{2}{|c|}{ No. of patients }} & \multirow{2}{*}{\multicolumn{2}{|c|}{$\begin{array}{l}\text { Normal } \\
\text { subjects }\end{array}$}} & \multicolumn{2}{|c|}{ Class I patients } & \multicolumn{4}{|c|}{ Class II patients } & \multicolumn{4}{|c|}{ Class III and IV patients } \\
\hline & & & & \multirow{2}{*}{$\frac{\text { NVD* }}{2}$} & \multirow{2}{*}{$\frac{\text { AS } \ddagger}{3}$} & \multicolumn{2}{|c|}{ NVD* } & \multicolumn{2}{|r|}{ AS $\ddagger$} & \multicolumn{2}{|c|}{ NVD* } & \multicolumn{2}{|r|}{ AS $\ddagger$} \\
\hline & & 13 & & & & 8 & & 8 & & 7 & & 6 & \\
\hline Age, $y r$ & & 25 & $( \pm 4)$ & 40 & $\cdot 28$ & 47 & $( \pm 4)$ & 47 & $( \pm 2)$ & 50 & $( \pm 2)$ & 51 & $( \pm 5)$ \\
\hline Body wt, $k g$ & & 62 & $( \pm 4)$ & 61 & 66 & 65 & $( \pm 5)$ & 68 & $( \pm 3)$ & 67 & $( \pm 4)$ & 73 & $( \pm 2)$ \\
\hline $\mathrm{HR}$, beats/min & $\begin{array}{l}\text { A } \\
\text { B } \\
\text { C }\end{array}$ & $\begin{array}{r}75 \\
107 \\
107\end{array}$ & $\begin{array}{l}( \pm 4) \\
( \pm 2) \\
( \pm 3)\end{array}$ & $\begin{array}{l}60 \\
99 \\
99\end{array}$ & $\begin{array}{r}73 \\
105 \\
107\end{array}$ & $\begin{array}{l}84 \\
89 \\
91\end{array}$ & $\begin{array}{l}( \pm 8) \\
( \pm 4) \\
( \pm 5)\end{array}$ & $\begin{array}{l}72 \\
86 \\
85\end{array}$ & $\begin{array}{l}( \pm 7) \\
( \pm 5) \\
( \pm 4)\end{array}$ & $\begin{array}{l}89 \\
79 \\
79\end{array}$ & $\begin{array}{l}( \pm 3) \\
( \pm 2) \\
( \pm 3)\end{array}$ & $\begin{array}{l}64 \\
75 \\
76\end{array}$ & $\begin{array}{l}( \pm 4) \\
( \pm 6) \\
( \pm 5)\end{array}$ \\
\hline $\mathrm{SV}, m l / m^{2}$ & $\begin{array}{l}\text { A } \\
\text { B } \\
\text { C }\end{array}$ & $\begin{array}{l}50 \\
33 \\
35\end{array}$ & $\begin{array}{l}( \pm 3) \\
( \pm 2) \\
( \pm 2)\end{array}$ & $\begin{array}{l}61 \\
34 \\
35\end{array}$ & $\begin{array}{l}56 \\
36 \\
37\end{array}$ & $\begin{array}{l}40 \\
31 \\
25\end{array}$ & $\begin{array}{l}( \pm 4) \\
( \pm 3) \\
( \pm 3)\end{array}$ & $\begin{array}{l}43 \\
33 \\
33\end{array}$ & $\begin{array}{l}( \pm 2) \\
( \pm 2) \\
( \pm 2)\end{array}$ & $\begin{array}{l}32 \\
28 \\
22\end{array}$ & $\begin{array}{l}( \pm 4) \\
( \pm 3) \\
( \pm 2)\end{array}$ & $\begin{array}{l}46 \\
38 \\
34\end{array}$ & $\begin{array}{l}( \pm 3) \\
( \pm 2) \\
( \pm 2)\end{array}$ \\
\hline $\mathrm{CI}$, liters $/$ min per $m^{2}$ & $\begin{array}{l}\text { A } \\
\text { B } \\
\text { C }\end{array}$ & & $\begin{array}{l}( \pm 0.2) \\
( \pm 0.2) \\
( \pm 0.2)\end{array}$ & $\begin{array}{l}3.6 \\
3.4 \\
3.5\end{array}$ & $\begin{array}{l}4.0 \\
3.8 \\
3.9\end{array}$ & & $\begin{array}{l}( \pm 0.1) \\
( \pm 0.2) \\
(+0.2)\end{array}$ & & $\begin{array}{l}1( \pm 0.4) \\
8( \pm 0.2) \\
8( \pm 0.2)\end{array}$ & & $\begin{array}{l}( \pm 0.3) \\
( \pm 0.2) \\
( \pm 0.1)\end{array}$ & & $\begin{array}{ll}9 & ( \pm 0.3) \\
8 & ( \pm 0.1) \\
6 & ( \pm 0.1)\end{array}$ \\
\hline LVEDP, $m m ~ H g$ & $\begin{array}{l}\text { A } \\
\text { B } \\
\text { C }\end{array}$ & $\begin{array}{r}10 \\
6 \\
9\end{array}$ & $\begin{array}{l}( \pm 2) \\
( \pm 0.5) \\
( \pm 0.6)\end{array}$ & $\begin{array}{r}13 \\
6 \\
10\end{array}$ & $\begin{array}{l}19 \\
14 \\
19\end{array}$ & $\begin{array}{l}10 \\
13 \\
21\end{array}$ & $\begin{array}{l}( \pm 2) \\
( \pm 1) \\
( \pm 2)\end{array}$ & $\begin{array}{l}18 \\
15 \\
21\end{array}$ & $\begin{array}{l}( \pm 4) \\
( \pm 3) \\
( \pm 3)\end{array}$ & $\begin{array}{l}20 \\
20 \\
26\end{array}$ & $\begin{array}{l}( \pm 3) \\
( \pm 2) \\
( \pm 2)\end{array}$ & $\begin{array}{l}24 \\
19 \\
28\end{array}$ & $\begin{array}{l}( \pm 3) \\
( \pm 2) \\
( \pm 3)\end{array}$ \\
\hline MAP, $m m ~ H g$ & $\begin{array}{l}\text { A } \\
\text { B } \\
\text { C }\end{array}$ & $\begin{array}{r}88 \\
97 \\
122\end{array}$ & $\begin{array}{l}( \pm 3) \\
( \pm 4) \\
( \pm 5)\end{array}$ & $\begin{array}{r}93 \\
97 \\
121\end{array}$ & $\begin{array}{r}96 \\
99 \\
127\end{array}$ & $\begin{array}{r}91 \\
90 \\
117\end{array}$ & $\begin{array}{l}( \pm 5) \\
( \pm 6) \\
( \pm 8)\end{array}$ & $\begin{array}{r}84 \\
78 \\
105\end{array}$ & $\begin{array}{l}( \pm 6) \\
( \pm 11) \\
( \pm 9)\end{array}$ & $\begin{array}{r}108 \\
97 \\
108\end{array}$ & $\begin{array}{l}( \pm 7) \\
( \pm 8) \\
( \pm 8)\end{array}$ & $\begin{array}{r}81 \\
83 \\
102\end{array}$ & $\begin{array}{l}( \pm 3) \\
( \pm 6) \\
( \pm 4)\end{array}$ \\
\hline $\mathrm{LVSW}, \mathrm{gm} / \mathrm{m}^{2}$ & $\begin{array}{l}\text { A } \\
\text { B } \\
\text { C }\end{array}$ & $\begin{array}{l}57 \\
43 \\
58\end{array}$ & $\begin{array}{l}( \pm 4) \\
( \pm 3) \\
( \pm 4)\end{array}$ & $\begin{array}{l}74 \\
42 \\
54\end{array}$ & $\begin{array}{r}119 \\
69 \\
92\end{array}$ & $\begin{array}{l}49 \\
36 \\
36\end{array}$ & $\begin{array}{l}( \pm 7) \\
( \pm 5) \\
( \pm 6)\end{array}$ & $\begin{array}{r}100 \\
71 \\
76\end{array}$ & $\begin{array}{l}( \pm 6) \\
( \pm 4) \\
( \pm 4)\end{array}$ & $\begin{array}{l}38 \\
30 \\
25\end{array}$ & $\begin{array}{l}( \pm 6) \\
( \pm 5) \\
( \pm 3)\end{array}$ & $\begin{array}{r}105 \\
84 \\
85\end{array}$ & $\begin{array}{l}( \pm 7) \\
( \pm 8) \\
( \pm 8)\end{array}$ \\
\hline LVSEP, $m s e c$ & $\begin{array}{l}\text { A } \\
\text { B }\end{array}$ & $\begin{array}{l}280 \\
250\end{array}$ & $\begin{array}{l}( \pm 10) \\
( \pm 5)\end{array}$ & $\begin{array}{l}300 \\
270\end{array}$ & $\begin{array}{l}330 \\
310\end{array}$ & $\begin{array}{l}250 \\
250\end{array}$ & $\begin{array}{l}( \pm 15) \\
( \pm 10)\end{array}$ & $\begin{array}{l}380 \\
340\end{array}$ & $\begin{array}{l}( \pm 20) \\
( \pm 15)\end{array}$ & $\begin{array}{l}230 \\
210\end{array}$ & $\begin{array}{l}( \pm 15) \\
( \pm 5)\end{array}$ & $\begin{array}{l}380 \\
360\end{array}$ & $\begin{array}{l}( \pm 15) \\
( \pm 10)\end{array}$ \\
\hline
\end{tabular}

Measurements were made in the control state (A), at rest after autonomic blockade (B), and during angiotensin infusion after blockade (C).

* Nonvalvular heart disease.

$\ddagger$ Aortic stenosis. 
a rise of $25-30 \mathrm{~mm} \mathrm{Hg}$ in the mean arterial pressure, or less if the left atrial pressure rose unusually. The final infusion rate varied between 0.012 and $0.025 \mathrm{mg} / \mathrm{kg}$ per min; it was slightly higher in class III and IV patients, in whom the arterial pressure rise obtained was slightly lower. (Table I). After constant infusion of angiotensin for $3 \mathrm{~min}$, a third set of hemodynamic measurements was made, completing the study.

All subjects were closely observed for $2 \mathrm{hr}$ after the procedure. There was, however, no evidence of increased cardiac or circulatory failure during this period. No patient required special aftercare, and there were no complications, immediate or delayed.

Pressures were recorded with Statham P-23g transducers. Cardiac output was measured by the dye-dilution method, injecting Indocyanine green into the left atrium and recording its concentration in blood drawn at $0.7 \mathrm{ml} / \mathrm{sec}$ from the brachial artery through a Gilford desitometer which was calibrated by a pooled sample method described in detail elsewhere (11). Duplicate measurements a few minutes apart in 26 other patients over the period of this study showed standard deviations of cardiac output of $\pm 6 \%$, and of stroke volume of $\pm 4 \%$.

All flow measurements and derived values were corrected for the body surface area. Stroke work was calculated as the product of stroke volume and the difference between mean arterial and left ventricular end-diastolic pressures, expressed in absolute units; in patients with aortic stenosis, the mean left ventricular pressure during ejection was substituted for the mean arterial pressure. The left ventricular systolic ejection period was measured from the brachial artery pressure pulse, recorded at $50 \mathrm{~mm} / \mathrm{sec}$ paper speed (12); opportunity arose on 20 occasions to compare this measurement with one made simultaneously from the central aortic pressure pulse, and a close agreement was found. As described later, the intrinsic heart rate was defined as the heart rate present $5 \mathrm{~min}$ after the injection of propranolol and atropine.

The following abbreviations have been used: $\mathrm{HR}=$ heart rate in beats/min; $\mathrm{SV}=$ stroke volume in $\mathrm{ml} / \mathrm{m}^{2} \mathrm{BSA} ; \mathrm{CI}$ $=$ cardiac index in liters $/ \mathrm{min}$ per $\mathrm{m}^{2} \mathrm{BSA} ; \mathrm{LVSW}=$ left ventricular stroke work in $g-\mathrm{m} / \mathrm{m}^{2} \mathrm{BSA} ; \mathrm{LVEDP}=$ left ventricular end-diastolic pressure in $\mathrm{mm} \mathrm{Hg}$; LVSEP = left ventricular systolic ejection period in msec; LVMER $=$ left ventricular mean ejection rate in $\mathrm{ml} / \mathrm{m}^{2} \mathrm{BSA}$ per sec; MAP = mean arterial pressure in $\mathrm{mm} \mathrm{Hg}$; and IHR= intrinsic heart rate in beats $/ \mathrm{min}$.

Patient material. 47 selected subjects consented to undergo the study after it was fully explained.

13 subjects were considered to have normal cardiac function. There was no cardiovascular abnormality in nine, whereas four had systolic ejection murmurs associated with trivial congenital abnormalities of the pulmonic valve. They were all asymptomatic, had normal EKG and radiologic findings, and were receiving no medication.

17 patients had nonvalvular heart disease (NVD). They all had known myocardial disease, which was ischemic in five, but of uncertain cause in the remainder. It was associated with pregnancy in one, with multiple pulmonary emboli in one, with idiopathic ventricular hypertrophy in two, with alcoholism in one, with myelomatosis in one, with hemochromatosis in one, and with endocardial fibrosis in one. No etiologic factors were recognized in the remaining four. These patients were chosen only if their cardiac disability could be clearly defined and wholly attributed to myocardial dysfunction, so that it would serve as an index to the severity of their myocardial disease. Using the American Heart Asso- ciation criteria, two were in functional class $I$, eight in class II, five in class III, and two in class IV. At the time of study, four were receiving no medication, three were on digitalis only, and ten were on both digitalis and diuretics. All were in sinus rhythm, and none had clinically significant mitral incompetence.

A further 17 patients had pure aortic valve stenosis of moderate or severe grade by clinical and hemodynamic criteria. Except for the presence of this valve lesion, their selection and classification were made on the same grounds as in the previous group. Three were in functional class I, eight in class II, and six in class III. Seven were on no therapy, four on digitalis only, and six on digitalis and diuretics.

These three patient groups are summarized in Table I. ${ }^{1}$

\section{RESULTS}

The results obtained in different patient groups are summarized in Table I. ${ }^{1}$ In Fig. 4 are shown the individual hemodynamic measurements at rest before and after autonomic blockade.

Control measurements. These were similar to the findings in many previous studies (e.g., 13, 14). In normal subjects there was a relatively wide range of cardiac performance at rest (Fig. 4). Patients with increasingly severe myocardial disease, as judged from their disability, tended to have a progressivly higher LVEDP, a lower SV and CI, and a slightly higher HR than normal. Not all such patients showed these features, however, and there was considerable overlap in all measurements, even between class III patients and normal subjects (Fig. 4).

Effect of autonomic blockade on cardiac function. Within 3-5 min after the injection of propranolol and atropine, a new steady state of the circulation was reached, as far as could be judged from the levels of HR, left atrial pressure, and arterial pressure. The changes in cardiac function from the control state provided a measure of the net effect of extrinsic stimuli on the heart before blockade. The mean changes observed in each patient class are shown in Fig. 3 .

In normal subjects, the HR rose uniformly, the mean value increasing by $43 \%$. This finding was consistent with the known excess of vagal over sympathetic influence on the $H R$ at rest (15). In patients with increasingly severe myocardial disease, this rise in $H R$ on autonomic blockade became progressively smaller. In class II patients the mean change was $+12 \%$, and in classes III and IV $+0.2 \%$ (Fig. 3). Four patients in class II and seven in classes III and IV showed falls in HR rather than rises; the largest of these was $15 \%$. There was, therefore, progressively less dominance of vagal over sympathetic influence on the $H R$ at rest with increasing severity of myocardial disease, with a reversal

\footnotetext{
${ }^{1}$ Copies of tables containing both clinical details and hemodynamic measurements in each of the 47 patients are available from the authors.
} 
of this normal relationship in some patients. The results did not show whether these changes were caused by a reduction of vagal or by an increase of sympa- thetic activity. It is known, however, that in patients with chronic heart disease, the normal vagal inhibitory influence on HR is frequently reduced (6), and quanti-
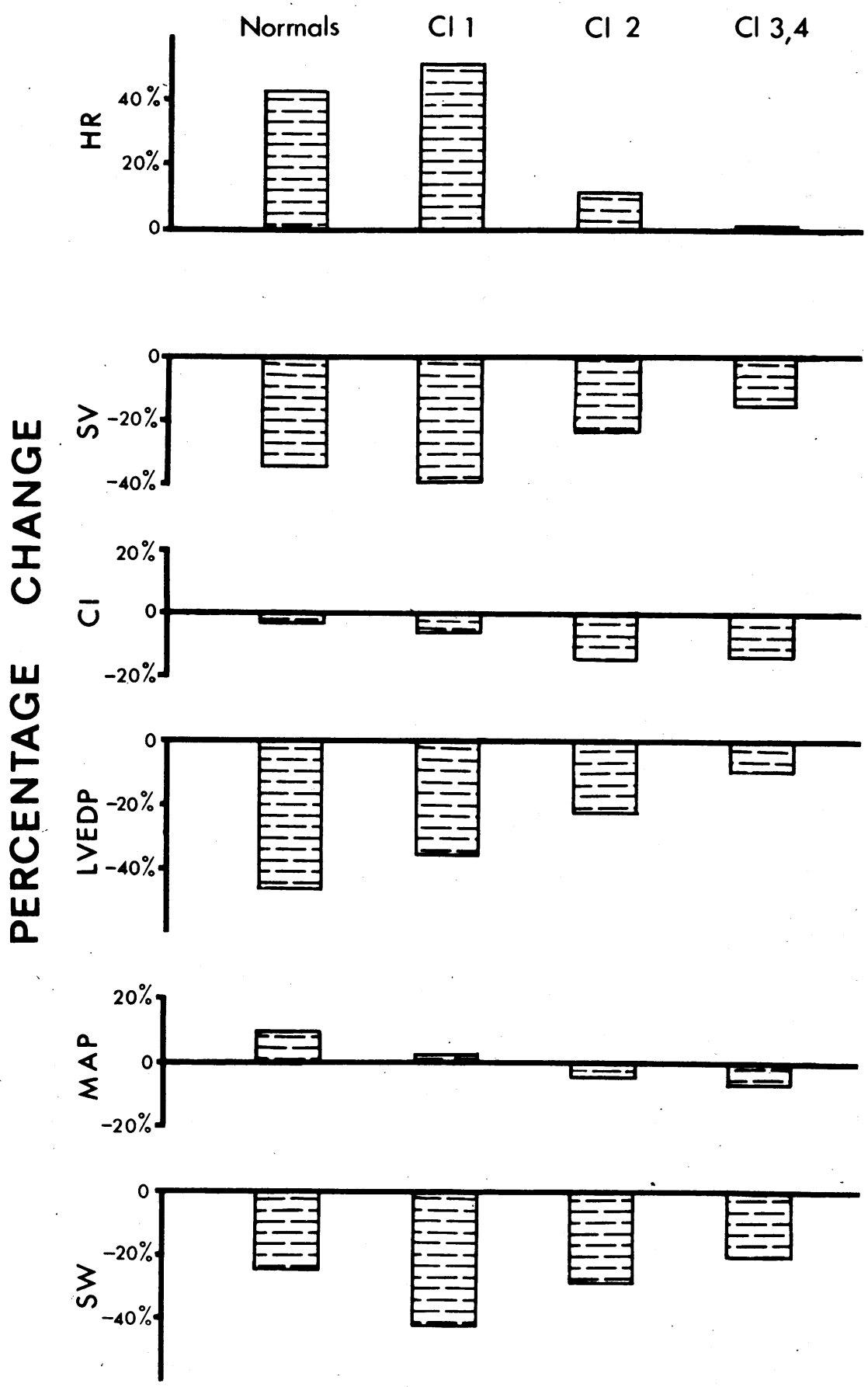

FIGURE 3 The mean effects of autonomic blockade on cardiac function at rest in patients of different functional class. Each bar represents the mean percentage change in that measurement from the control study to that after the injection of propranolol and atropine. 
tatively the changes described would be sufficient to account for the present findings without supposing that sympathetic activity was increased.

Despite these changes in HR, cardiac output and arterial pressure were little affected by autonomic blockade in any patient group (Fig. 3). There were no significant changes in $\mathrm{CI}$ in normal or class I patients, and there were falls averaging $13 \%$ and $12 \%$ in class II and classes III and IV respectively. Four individuals were exceptional in showing falls in CI of $20-30 \%$; these all appeared to result from systemic venous dilatation; in each case, the mean pressures in both atria were unusually high in the control study and they fell significantly after propranolol and atropine; this reduced the stroke volume without evidence of depression of myocardial contractility.

In most subjects, the significant rise in $H R$ was associated with a fall in SV and in LVEDP, and prevented any assessment of the direct inotropic effect of autonomic blockade. In those patients whose HR remained constant, however, the changing relationships between LVSW and LVEDP commonly gave evidence of a small negative inotropic change. In no patient was there evidence of a major depression of myocardial function.

Cardiac performance after autonomic blockade. The atrial and ventricular complexes of the EKG remained unchanged from the control study. Sinus arrhythmia however, was absent, and occasional ventricular ectopic beats present before blockade in 12 patients were totally abolished in 11 .

In all patients, the HR had reached a steady level within $5 \mathrm{~min}$ of the injection of propranolol and atropine. Over the next $20-30 \mathrm{~min}$, there were no spontaneous HR changes, nor were significant changes provoked by emotional or painful stimuli, by light supine exercise, or by raising the arterial pressure with angiotensin. This value of the sinus heart rate measured 5 min after autonomic blockade was defined as the intrinsic heart rate (IHR). This intrinsic rate was characteristically fast in normal subjects, and progressivly slower in patients with myocardial disease (Fig. 4). The highest value was $126 / \mathrm{min}$ in a $17 \mathrm{yr}$ old normal boy, and the lowest $57 / \mathrm{min}$ in a $62 \mathrm{yr}$ old woman with aortic stenosis and class III disability. In normal subjects the mean IHR was $107.5 / \mathrm{min}$ (SD 9.3); in class I patients the mean value was $102.4 / \mathrm{min}$; in class II patients the mean of $87.6 / \mathrm{min}$ was significantly below that in normal subjects $(P<0.001)$; and in class III and IV patients the mean of $77.3 / \mathrm{min}$ was significantly below that in class II $(P<0.005)$. In patients with aortic stenosis, although the control HR was somewhat lower than in other equally disabled patients (Fig. 4), there was no corresponding difference in the IHR.
Most of the changes in ventricular performance in normal subjects after autonomic blockade could be attributed to the faster heart rate; the SV, LVSEP, and LVEDP were all lower than in the control study, whereas the CI was unchanged. There was, in addition, a reduction in the scatter of certain parameters of cardiac performance in normal subjects: notably in LVEDP (range in control study 4-15 $\mathrm{mm} \mathrm{Hg}$, after blockade 3$8 \mathrm{~mm} \mathrm{Hg}$, variance ratio $\mathrm{F}=2.62, P<0.05)$, in $\operatorname{LVSEP}(\mathrm{F}=3.30, P<0.05)$, in SV $(\mathrm{F}=2.60, P<$ $0.05)$, and to a lesser extent in $\mathrm{HR}(\mathrm{F}=2.25, P>$ $0.05)$.

In patients with myocardial disease, the abnormalities of cardiac performance after autonomic blockade differed qualitatively from those present in the control study (Fig. 4). As described above the IHR was progressivly slower in the presence of increasingly severe disease. The SV, instead of falling with increasing disease as in the control study, became almost equal in different classes of patient; individual values significantly below the mean of $33 \mathrm{ml} / \mathrm{m}^{2}$ in normal subjects occurred only in those few patients already described in whom autonomic blockade apparently caused systemic venous dilatation. In the absence of aortic stenosis, the LVSEP after blockade was also equal in different classes of patient; again, lower values than the mean of $250 \mathrm{msec}$ in normal subjects occurred only in those patients whose SV was also low. The LVMER, obtained by dividing the SV by the LVSEP, was therefore even more closely equal in different patient classes, averaging $131 \mathrm{ml} / \mathrm{m}^{2}$ per sec in normal subjects, 126 $\mathrm{ml} / \mathrm{m}^{2}$ per sec in class I, $123 \mathrm{ml} / \mathrm{m}^{2}$ per sec in class II, and $132 \mathrm{ml} / \mathrm{m}^{2}$ per sec in classes III and IV. In the presence of aortic stenosis the LVSEP was prolonged and the LVMER reduced, both roughly in proportion to the severity of the valvular obstruction.

The assessment of abnormal ventricular function. After autonomic blockade, patients with myocardial disease were distinguished from normal by the presence of a slower HR, higher LVEDP, and lower CI (Fig. 4). Using their grades of disability as an index of left ventricular function, the measurements of HR and LVEDP after blockade both identified patients with depressed ventricular function more clearly than did any measurements made in the control study. The $95 \%$ limits of LVEDP in normal subjects after blockade were $5.8 \pm 3.4 \mathrm{~mm} \mathrm{Hg}$. By this criterion alone, abnormal ventricular function was identified in two out of five class I patients, in 11 out of 16 class II patients, and in all 13 class III and IV patients. The 95\% limits of the IHR in normal subjects were $107.5 \pm 18.6 / \mathrm{min}$; by this measurement alone, abnormal function was present in none of the class I patients, in 10 out of 16 class II patients, and in 11 out of 13 in classes III and IV. 

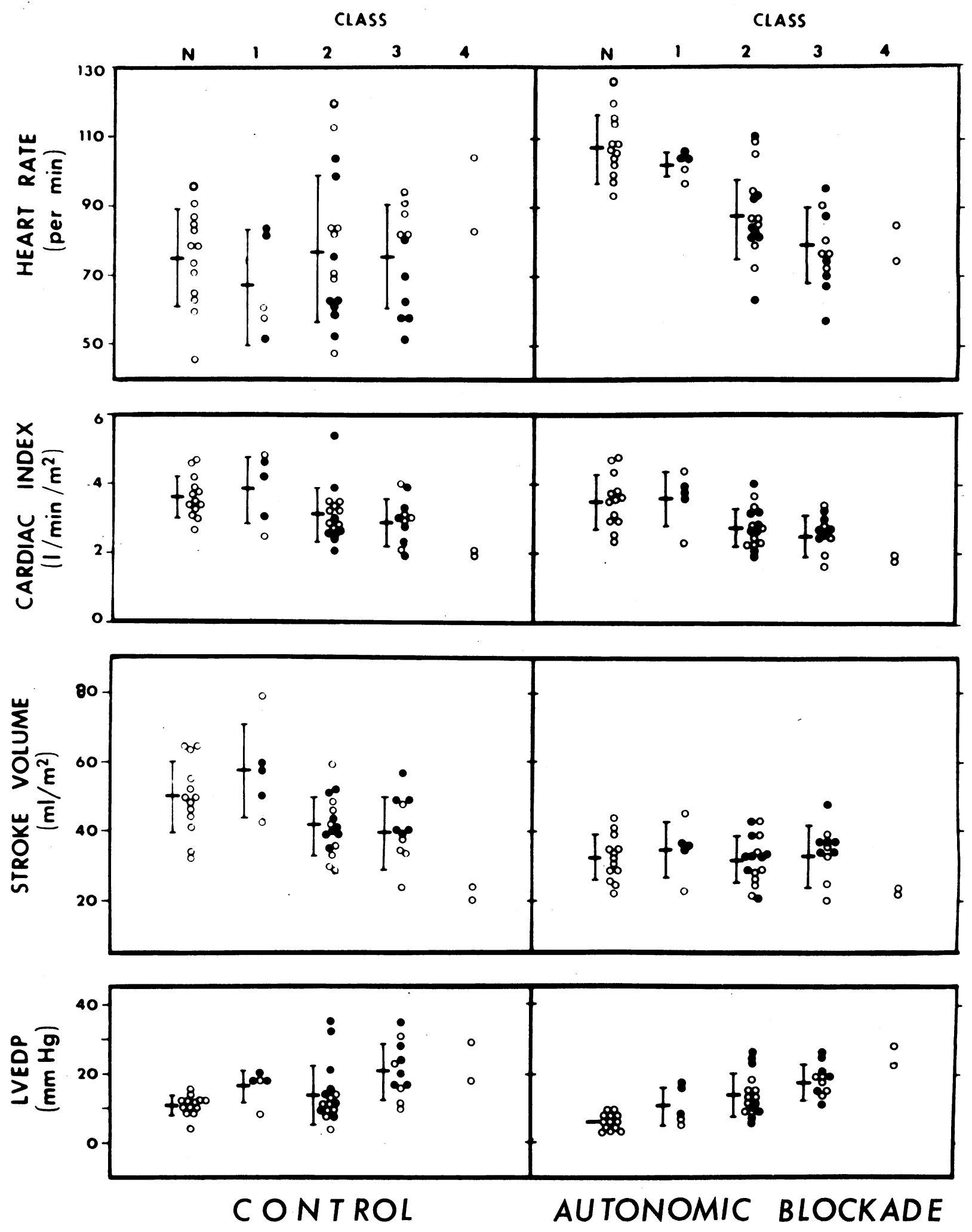

Figure 4. 
Every patient with an IHR below normal also had a raised LVEDP, but five patients with raised LVEDP measurements had a normal IHR; three of these had aortic stenosis.

No measurements made in the control study, taken either singly or in combination, resulted in a comparable degree of separation of these patient groups (Fig. 4).

The left ventricular response to increased arterial pressure. The infusions of angiotensin caused sustained rises in MAP which averaged $24 \mathrm{~mm} \mathrm{Hg}$ in normal and class I patients, $25 \mathrm{~mm} \mathrm{Hg}$ in Class II patients, and 15 $\mathrm{mm} \mathrm{Hg}$ in class III and IV patients. The HR was virtually unchanged during the infusions; the absolute change in 47 patients averaged $2.0 / \mathrm{min}$ (SD 1.9), and was random in direction. The mean measurements of cardiac performance in different patient classes during the infusion are given in Table $I$. The individual relationships between LVSW and LVEDP at two levels of arterial pressure after autonomic blockade are shown in Fig. 5, in the form of "ventricular function curves."

In normal subjects there was a small but uniform rise in SV (mean change $+6 \%, P<0.01$ ); the LVEDP rose by an average of $3.7 \mathrm{~mm} \mathrm{Hg}$, and LVSW increased by an average of $35 \%$. In each normal subject, the LVSW/LVEDP relationship rose steeply (open circles, Fig. 5).

In patients with nonvalvular disease, the mean changes were: in class I a small rise in SV, a rise of $3.5 \mathrm{~mm} \mathrm{Hg}$ in LVEDP, and a $28 \%$ rise in LVSW: in class II a $19 \%$ fall in SV, a rise of $8.2 \mathrm{~mm} \mathrm{Hg}$ in LVEDP, and no change in LVSW; and in classes III and IV a $22 \%$ fall in SV, a rise of $6.3 \mathrm{~mm} \mathrm{Hg}$ in LVEDP, and a $19 \%$ fall in LVSW. The individual LVSW/LVEDP relationships in class II patients (crosses, Fig. 5) did not differ from normal in two cases, but were markedly abnormal in the other six, as they were in all seven class III and IV patients (closed circles, Fig. 5). Five patients, all in classes III and IV, showed falls in LVSW greater than $10 \%$.

Comparable results were obtained in patients with aortic stenosis though there was less abnormality of the ventricular response than in equally disabled patients with nonvalvular disease. The mean changes were: in class I a small rise in SV, a rise of $5.0 \mathrm{~mm} \mathrm{Hg}$ in LVEDP, and a rise of $34 \%$ in LVSW; in class II no change in SV, a rise of $6.1 \mathrm{~mm} \mathrm{Hg}$ in LVEDP, and a rise of $7 \%$ in LVSW ; and in class III a fall of $9 \%$ in $\mathrm{SV}$, a rise of $8.9 \mathrm{~mm} \mathrm{Hg}$ in LVEDP, and no change in LVSW (Table I). The individual LVSW/LVEDP re- lationships are shown in Fig. 5 (right): there were rises in LVSW in all three patients in Class I, in four of the eight in class II, and in one of the six in class III. No patient showed a significant fall in LVSW.

There were no measurable changes in LVSEP in any patient during the period of increased arterial pressure. Since HR was also constant, it appeared therefore, that the ventricular responses were determined solely by operation of the Frank-Starling mechanism. It is possible, however, that the small but consistent rise in SV seen in every normal and class I patient represented a positive inotropic response to increased ventricular afterload.

The relationship between the IHR and left ventricular function. In the patients chosen for the study, we considered that abnormal left ventricular function could be assessed with reasonable accuracy from their cardiac symptoms. The unexpected finding that the IHR correlated well with cardiac disability (Fig. 4) therefore raised the possibility that the IHR was in some way related to left ventricular function. Further analysis of the data supported this.

At rest after autonomic blockade, striking correlations appeared between the IHR and certain parameters of ventricular function. The $\mathrm{CI}$ was positively related to the IHR: $\mathrm{CI}=0.03 \mathrm{IHR}+0.36 ;(r=0.60, P<$ $0.001)$. The LVEDP was negatively related to the IHR: LVEDP $=-0.32$ IHR $+42 ; \quad(r=0.71 ; P<$ 0.001 ). The quotient of these two measurements was still more closely, though not linearly, related to the IHR: $\log (\mathrm{CI} / \mathrm{LVEDP})=0.04 \mathrm{IHR}+2.1 ;(r=0.76, P<$ $0.001)$. In the absence of aortic stenosis, significant though less close relationships were also present between the MAP and the IHR, and between the LV minute work and the IHR. There were no significant relationships between these same measurements in the control study.

The response to increased arterial pressure provided another totally independent comparative measure of left ventricular function in different patients. Several indices of this response were examined, including the change in SV, the change in SV per unit rise in LVEDP, and both the absolute and percentage changes in LVSW per unit rise in LVEDP (use of a percentage change in LVSW enabled patients with aortic stenosis to be included on the same scale as those with nonvalvular disease). Each index was about equally effective in separating patients according to their grade of disability. Each was also significantly correlated with the IHR; two examples are shown graphically in

Figure 4. Individual hemodynamic measurements at rest in the control state (left) and after autonomic blockade (right) in 47 patients according to their functional class. $\mathrm{N}=$ normal subjects ; open circles = patients with nonvalvular disease; closed circles = patients with aortic stenosis. Vertical bars indicate the mean value in each group, with limits of $1 \mathrm{SD}$. 
Fig. 6, together with their calculated linear regression equations. The individual correlation coefficients were of the same order of magnitude as those found for the relationships between the IHR and cardiac performance at rest after autonomic blockade.

As a result of our selection of patients, the more disabled patients were older than the normal subjects ( Table I). The abnormalities of cardiac function described cannot therefore be ascribed entirely to the effects of disease as distinct from age. Indeed it is likely that both processes contribute in varied proportion to myocardial dysfunction in all adult patients with heart disease. A significant relationship existed between the IHR and age in the present data, but allowance for this by covariance analysis still left significant differences in IHR between normal and disabled patients. Moreover, there was no significant age difference between the patients in class II and those in classes III and IV, $(P>0.2)$, although their measurements of IHR and of ventricular function differed widely.

Complications. The study was completely without complication, fully confirming our preliminary findings in regard to the safety of the administration of propranolol and atropine together. Even in patients with far advanced heart disease, there was no significant adverse effect of autonomic blockade, provided only that patients with acute congestion and markedly raised venous pressures were excluded. The four such patients who were included in this study all showed significant falls in cardiac output after blockade, although these were not dangerous.

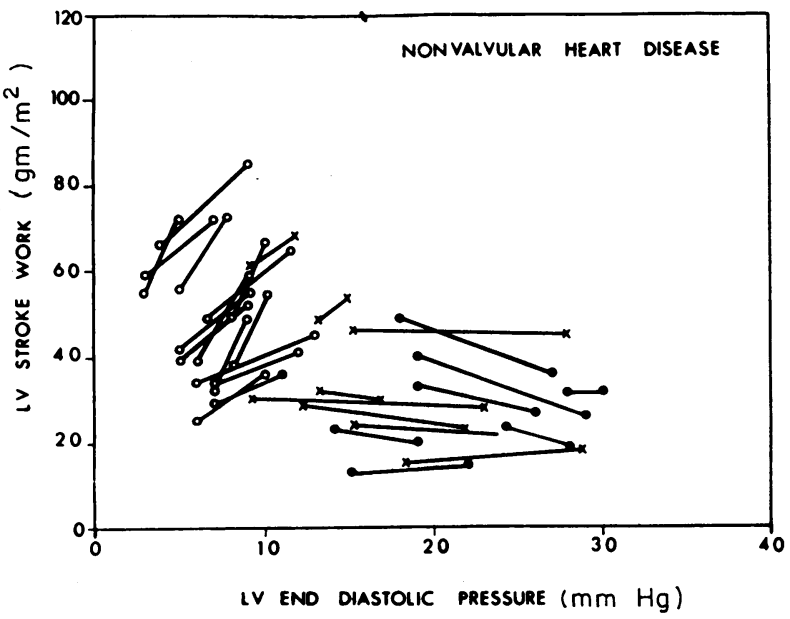

\section{DISCUSSION}

The doses of propranolol and atropine employed here were shown to produce an effective temporary blockade of autonomic activity in the heart, and these findings were consistent with previous studies of both drugs $(8,16-18)$. Whether any other action of these drugs influenced our results is not known, but appears unlikely. Atropine is thought to have no direct effect on the myocardium in man, even in massive doses (19). Although large doses of propranolol directly depress myocardial function $(8,16)$, smaller beta-adrenergic blocking doses have no depressant effect in hearts already deprived of adrenergic activity (20-22); our preliminary study confirmed this in man.

Autonomic blockade had systematically different effects on cardiac performance in normal and diseased hearts (Fig. 3). Although of considerable interest, this finding will not be discussed further since its interpretation requires separate knowledge of the vagal and sympathetic components of autonomic activity in such patients, which was not obtained in this study.

Cardiac function after autonomic blockade was of interest both for its possible diagnostic value, and for its probable relevance to the function of the heart after surgical transplantation.

For diagnostic purposes, autonomic blockade had the over-all effect of magnifying differences in cardiac performance at rest beween normal and diseased hearts. The variability of performance in normal subjects at rest was significantly reduced. Also, because of the functional changes in different patients, the stroke volume became equal in normal and diseased hearts,

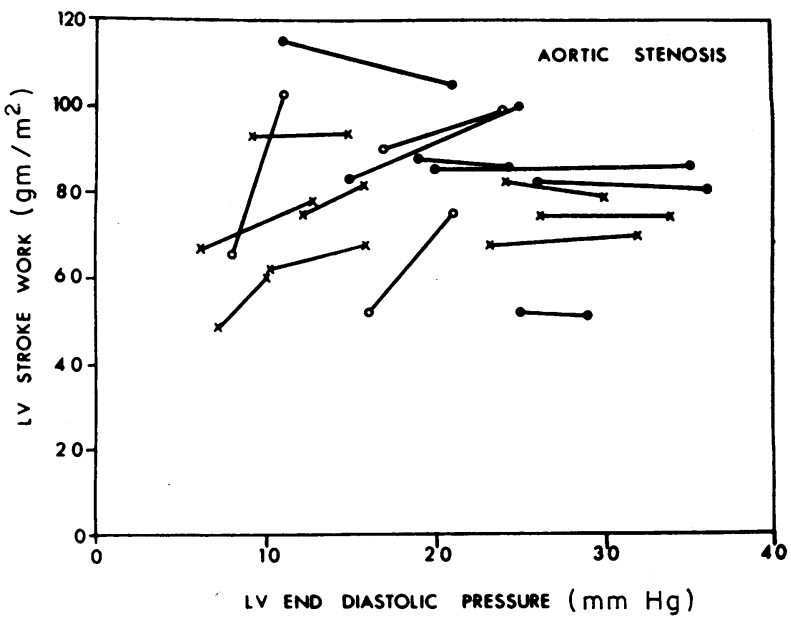

FIGURE 5 Relationships between LV stroke work and LV end-diastolic pressure after autonomic blockade before and during the infusion of angiotensin to increase arterial pressure. Left: normal subjects and patients with nonvalvular disease; right: patients with aortic stenosis; open circles: normal and class I patients; crosses: class II patients; closed circles: class III and IV patients. 

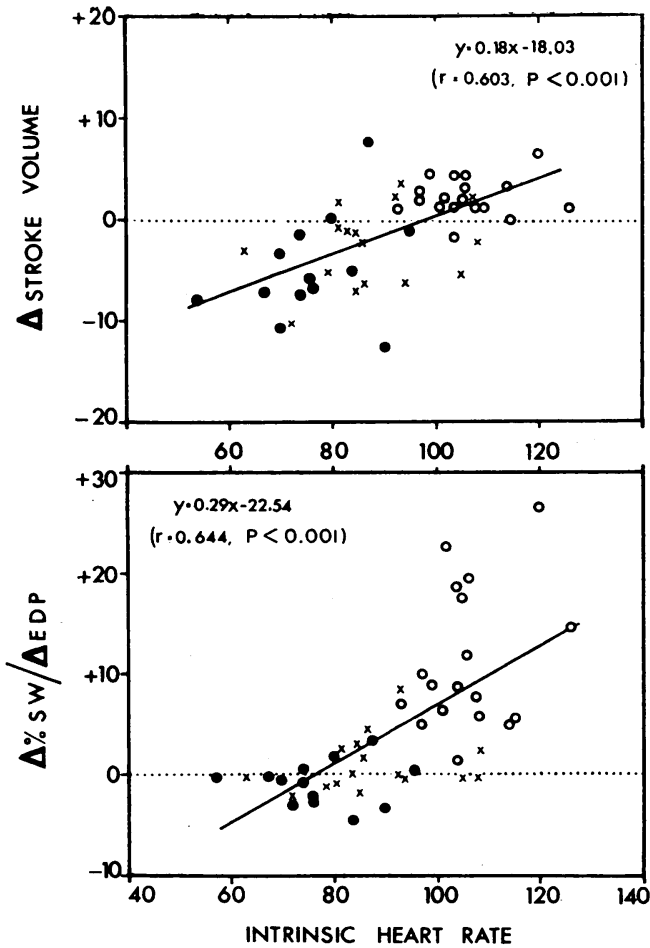

FIGURE 6 The relationships in 47 patients between the intrinsic heart rate (abscissa) and two indices of the $L V$ response to increased arterial pressure after autonomic blockade. Top: the change in stroke volume $\left(\mathrm{ml} / \mathrm{m}^{2} \mathrm{BSA}\right)$; bottom: the ratio of the percentage change in LV strole work to the absolute change in LV end-diastolic pressure. Symbols as in Fig. 5; solid lines are calculated linear regression equations.

whereas the heart rate and ventricular end-diastolic pressure became widely different (Fig. 4). As a result, almost every patient with known myocardial disease showed an abnormality of either the IHR or LVEDP at rest. Thus the well known ability of cardiac patients to maintain normal hemodynamics at rest $(13,14)$ was no longer evident after blockade. The significance of abnormalities in the IHR and LVEDP at rest with regard to left ventricular function, was confirmed by the subsequent infusions of angiotensin; abnormal angiotensin responses corresponded closely to abnormalities in these measurements at rest; unlike the results obtained with angiotensin without prior autonomic blockade (23), no patient with normal hemodynamics at rest after blockade showed abnormal findings at the higher arterial pressure. All of these findings were consistent with the concept that in diseased hearts the balance of autonomic activity is directed toward the maintenance of a normal cardiac performance.

The most obvious feature of cardiac function after autonomic blockade was the fixed heart rate, at a higher level in normal than in diseased hearts. The cardiac output at rest, which was generally higher in normal than in diseased hearts, was virtually the same before and after blockade in all patients provided that venous return was not impaired. After blockade, because heart rate is fixed, and extrinsic changes in myocardial function cannot occur, the regulation of cardiac output must depend wholly on stroke volume changes in response to arterial and venous pressure changes. It is not clear why under these conditions, the stroke volume in normal and diseased hearts became approximately equal after blockade; either this was a chance finding, or perhaps in individual patients there was some relationship between the level of the IHR and the level to which the cardiac output was regulated at rest. Equally without explanation was the close similarity of the left ventricular ejection period in normal and diseased hearts (in the absence of aortic stenosis) ; interestingly, experimental heart failure in dogs after autonomic blockade caused progressive falls in myocardial contractility and intrinsic rate, but did not change the duration of left ventricular contraction (10).

The response to angiotensin was not appreciably impaired after autonomic blockade, in either normal or diseased hearts. Quantitatively, the relationships between left ventricular stroke work and end-diastolic pressure in this study were quite similar to those in comparable patients in the study by Ross and Braunwald (23), who gave angiotensin without prior autonomic blockade. It might be concluded that autonomic nervous activity had no significant role in the heart's response to increased arterial pressure. The same conclusion has been reached in dogs with surgically denervated hearts (24).

The relationship found between the IHR and left ventricular function after blockade may have great significance. This had no quantitative resemblance to the frequency-force relationship in cardiac muscle. We have found no previous description of any such relationship in the literature, nor could this be expected since the intrinsic properties of diseased hearts have not been studied before. In isolated hearts, however, spontaneous slowing and weakness commonly occur together during hypoxic or mechanical heart failure $(25,26)$, although this phenomenon has been obscured in many studies by electrical pacing of the heart. In isolated atria, agents which inhibit energy synthesis in the myocardium depress the spontaneous rate and contractility in a relatively constant ratio $(27,28)$. And recently, we have shown that in dogs after autonomic blockade, the IHR and ventricular contractility are depressed in a close linear relationship during acute failure produced by interference with energy synthesis in the myocardium $(10,29)$. A close relationship therefore does exist between the IHR and myocardial function under appropriate conditions in animals. In the absence of any other known connection between these two functions, this 
appears to be the most likely explanation for the relationship found in man in this study. Quantitatively, there is a close resemblance between the two (10). The degree of correlation between the IHR and left ventricular function in this study did not approach that between the IHR and myocardial contractility in dogs, but the indices of ventricular function available here were all indirect, and are influenced by the size, thickness, and work load of the ventricle as well as by its muscle contractility; closer relationships with the IHR could not therefore have been expected. More direct indices of muscle function were not available from our data. The rate of pressure rise in the ventricle was not recorded with adequate fidelity for this purpose, and ventricular volume was not measured. The present data therefore suggest, but do not prove, that the intrinsic rate is related to the contractility of the myocardium in patients with myocardial disease. Preliminary serial measurements of the intrinsic rate in patients with active myocardial disease (3) have supported this suggestion.

The existence of such a relationship would have significance in at least two directions: first, because the IHR can be measured simply, safely, and quickly in clinical practice (3), it may prove valuable for the assessment of myocardial function in man; and secondly, studies of the analogous relationship in animals (29) may help to determine the nature of the abnormalities in the failing myocardium in man.

The contrast between the safety of autonomic blockade by propranolol and atropine together, and the known risks of cardiac depression by propranolol alone $(9,30)$ deserves some comment. Three factors were observed in this study to account for its safety: (a) the inclusion of atropine wtih propranolol, which avoided acute unopposed vagal depression of the heart; $(b)$ the exclusion of patients with untreated or severe congestive failure, in whom cardiac performance fell after blockade, apparently as a result of venous dilatation; and (c) the finding that even in patients with advanced disease, the heart was not greatly dependent on beta receptor activity at rest. Additional related factors were that the heart appeared notably less prone to arrhythmias after blockade than before, and that only a brief period of blockade was required, after which if desired the action of propranolol could rapidly be reversed by injection of isoproterenol. The safety of autonomic blockade to measure the IHR has since been amply confirmed in normal man (31) and in cardiac patients (3, and unpublished data).

\section{ACKNOWLEDGMENTS}

This work was supported by the National Heart Foundation of Australia and by G. D. Searle and Co., England. Dr. Taylor held a research fellowship from Smith Kline and
French (Australia), Ltd. We are also indebted to Imperial Chemical Industries, Ltd., Cheshire, England for supplies of propranolol (Inderal).

\section{REFERENCES}

1. Taylor, R. R., and A. D. Jose. 1963. Blockade of myocardial adrenergic receptors: an approach to pharmacological isolation of the heart. Proceedings of the Cardiac Society of Australia. J. Hickie, editor. Sydney. 30. (Abstr.)

2. Jose, A. D., D. Collison, and R. R. Taylor. 1966. The nature of myocardial failure in man, studied by pharmacological isolation of the heart. Australas. Ann. Med. 15: 93. (Abstr.)

3. Jose, A. D. 1966. The effect of combined sympathetic and parasympathetic blockade on heart rate and cardiac function in man. Amer. J. Cardiol. 18: 476.

4. Sarnoff, S. J., and J. H. Mitchell. 1962. Control of the function of the heart. In Handbook of Physiology, Section 2. Vol. 1. W. F. Hamilton and P. Dow, editors. American Physiological Society, Washington, D. C. 490.

5. Rushmer, R. F. 1962. Effects of nerve stimulation and hormones on the heart; the role of the heart in general circulatory regulation. In Handbook of Physiology, section 2. Vol. 1. W. F. Hamilton and P. Dow, editors. American Physiological Society, Washington, D. C. 533.

6. Crawford, J. H. 1923. The influence of the vagus on the heart rate. J. Pharmacol. Exp. Ther. 22: 1.

7. Braunwald, E., C. A. Chidsey, D. C. Harrison, T. E. Gaffney, and R. L. Kahler. 1963. Studies on the function of the adrenergic nerve endings in the heart. Circulation. 28: 958 .

8. Black, J. W., W. A. M. Duncan, and R. G. Shanks. 1965. Comparison of some properties of pronethalol and propranolol. Brit. J. Pharmacol. 25: 577.

9. Stephen, S. A. 1966. Unwanted effects of propranolol. Amer. J. Cardiol. 18: 463.

10. Jose, A. D., and F. Stitt. 1967. Cardiac function after combined beta-adrenergic and cholinergic blockade. Relationship of intrinsic rate to contractile force of the heart in dogs. Circ. Res. 21 (Suppl. 3): 231.

11. Jose, A. D., C. J. McGaff, and W. R. Milnor. 1960 The value of dye injections in the assessment of patients with mitral and aortic valve disease by left heart catheterization. Amer. Heart J. 60: 408.

12. Levine, H. J., W. A. Neill, R. J. Wagman, N. Krasnow and R. Gorlin. 1962. The effect of exercise on mean left ventricular ejection rate in man. J. Clin. Invest. 41: 1050.

13. Lewis, B. M., H. E. J. Houssay, F. W. Haynes, and L. Dexter. 1953. The dynamics of both right and left ventricles at rest and during exercise in patients with heart failure. Circ. Res. 1: 312 .

14. Harvey, R. M., W. M. Smith, J. O. Parker, and M. I. Ferrer. 1962. The response of the abnormal heart to exercise. Circulation. 26: 341.

15. Robinson, B. F., S. E. Epstein, G. D. Beiser, and E. Braunwald. 1966. Control of heart rate by the autonomic nervous system: studies in man on the interrelation between baroreceptor mechanisms and exercise. Circ. Res. 19: 400 .

16. Shanks, R. G. 1966. The pharmacology of beta-sympathetic blockade. Amer. J. Cardiol. 18: 308.

17. Lewis, T., A. N. Drury, A. M. Wedd, and C. C. Iliescu. 1921. Atropine and strophanthin. Heart. 9: 21. 
18. Chamberlain, D. A., and P. Turner. 1967. Effects of atropine on heart rate in healthy men. Lancet. 2: 12.

19. Eger, E. I. 1962. Atropine, scopolamine and related compounds. Anesthesiology. 23: 365.

20. Atanacković, D., and M. H. Alper. 1965. Beta-blocking actions of propranolol in the isolated mammalian heart. Fed. Proc. 24: 713.

21. Shanks, R. G. 1966. The effect of propranolol on the cardiovascular responses to isoprenaline, adrenaline, and noradrenaline in the anaesthetized dog. Brit. J. Pharmacol. 26: 322 .

22. Flacke, J. W., P. F. Osgood, and H. H. Bendixen. 1967. Propranolol and isoproterenol in dogs deprived of sympathetic nerve activity. J. Pharmacol. Exp. Ther. 158: 519.

23. Ross, J, and E. Braunwald. 1964. The study of left ventricular function in man by increasing resistance to ventricular ejection with angiotensin. Circulation. 29: 739.

24. Tsakiris, A. G., W. Rutishauser, N. Banchero, D. E. Donald, and E. H. Wood. 1964. Effects of changes in peripheral vascular resistance on cardiac performance in normal and cardiac denervated dogs studied without thoracotomy. Physiologist. 7: 272. (Abstr.)

25. Wiggers, C. J. 1949. Physiology in Health and Disease. Henry Kempton, London. 5th edition. 58.

26. Wollenberger, A. 1947. On the energy-rich phosphate supply of the failing heart. Amer. J. Physiol. 150: 733.

27. Webb, J. L. 1950. The actions of metabolic substrates and inhibitors on the rabbit auricle. Brit. J. Pharmacol. 5 : 87.

28. Gardner, E. A., and A. Farah. 1954. The action of some enzyme inhibitors on the isolated rabbit auricle. $J$. Pharmacol. Exp. Ther. 111: 255.

29. Jose, A. D., and F. Stitt. 1969. The effects of hypoxia and metabolic inhibitors on the intrinsic heart rate and myocardial contractility in dogs. Circ. Res. 25: 53.

30. Shamroth, L. 1966. Immediate effects of intravenous propranolol on various cardiac arrhythmias. Amer. J. Cardiol. 18: 308.

31. Jose, A. D., and D. Collison. 1969. The normal range and determinants of the intrinsic heart rate in man. Cardiovasc. Res. In press. 